\title{
A influência do salário mínimo sobre a taxa de salários no Brasil na última década *
}

\author{
Carlos Aguiar de Medeiros ${ }^{* *}$
}

\begin{abstract}
Resumo
A partir da revisão de uma revisão da literatura estruturalista institucionalista do mercado de trabalho explorou-se, neste texto, as conexões entre o aumento do assalariamento formal e a elevação do poder de compra do salário mínimo ocorrido na última década na economia brasileira. Discutiu-se como este passou a exercer crescente influência sobre a formação da taxa de salários de amplos segmentos dos trabalhadores assalariados formais e informais e da renda dos trabalhadores autônomos sem recursos de qualificação. Argumentou-se que, ao lado de seu impacto positivo sobre o emprego formal e redução da pobreza, esta influência decorreu de mudanças na composição dos padrões de consumo e do emprego com o crescimento mais do que proporcional do assalariamento no setor de serviços e da evolução dos preços relativos.
\end{abstract}

Palavras-chave: Salário mínimo; Emprego assalariado; Crescimento econômico; Pobreza; Distribuição de renda.

\section{Abstract \\ The influence of minimum wage on Brazilian wage rate in the last decade}

In this paper, we review the institutionalist and structuralist labor market theory by analyzing the connections between the increase in formal employment and in minimum wage that occurred in the Brazilian economy in the last decade. The evolution of the minimum wage exerted an important influence on the predominant compensation received by unskilled labor in the formal and informal labor market. We argue that besides the positive impact of a minimum wage on the labor market, this influence took place as a result of changes in consumption patterns, employment structure and in relative prices.

Keywords: Minimum wage; Employment; Economic growth; Poverty; Income distribution.

JEL J3, J4, J8.

\section{Introdução}

A elevada expansão do trabalho assalariado formal e o persistente aumento do salário mínimo real estão reconhecidamente na base da redução da pobreza e das desigualdades nas rendas do trabalho observadas nos últimos anos na economia brasileira. Embora o impacto de ambos seja evidente para a redução da pobreza em uma economia com elevado desemprego estrutural, o próprio aumento do emprego formal e o efeito do salário mínimo sobre a taxa de salários e a distribuição de renda

\footnotetext{
*Artigo recebido em 14 de dezembro de 2013 e aprovado em 8 de março de 2015.

** Professor Associado do Instituto de Economia da Universidade Federal do Rio de Janeiro (UFRJ), Rio de Janeiro, RJ, Brasil / Pesquisador do Conselho Nacional de Desenvolvimento Científico e Tecnológico (CNPq).
} E-mail: carlosaguiarde@gmail.com. 
do trabalho de forma alguma é autoevidente. Com efeito, considerando que em uma economia com elevado nível de heterogeneidade na estrutura produtiva e nas formas de ocupação como a que se observa no país, a elasticidade do emprego formal em relação ao crescimento econômico que se afirmou entre 2003-2010 poderia se limitar aos setores mais dinâmicos da economia e na grande empresa. A elevação generalizada do emprego assalariado formal em conexão com o aumento do salário mínimo constitui uma nova realidade que demanda uma interpretação.

A relação entre o salário mínimo, a taxa de salários e a renda do trabalho autônomo constitui uma questão distributiva chave em uma economia com as características da brasileira. Com efeito, dependendo do seu nível e das características institucionais do mercado de trabalho, este pode ter uma influência relativamente limitada tanto sobre os salários dos trabalhadores não qualificados no setor formal da economia quanto sobre as rendas no trabalho assalariado informal ou do trabalho autônomo.

A crescente influência do salário mínimo sobre a taxa de salários e sobre a renda nas atividades informais observada na última década constitui o objetivo principal deste texto. Seguindo uma direção pioneiramente desenvolvida nas análises keynesiana-estruturalista feitas por Souza (1979) e Baltar e Souza (1980), discutemse duas hipóteses centrais. Em primeiro lugar, ao afirmar-se mais próximo da taxa de salários, o aumento desta se deu concomitantemente a uma redução da dispersão dos salários com consequente crescimento menor do salário médio. A maior exposição da indústria de transformação à concorrência externa e o maior crescimento do emprego e dos preços do setor de serviços, agricultura e do comercio onde predominam os baixos salários contribuíram para este resultado. Em segundo lugar, discute-se a maneira em que, nas condições de elevação do nível geral de emprego em relação ao crescimento da PEA, o salário mínimo agiu como um farol irradiando-se para a determinação da renda do trabalho assalariado nas atividades informais, e também como um fator de propulsão para as rendas derivadas do trabalho autônomo.

Além desta introdução, este texto está divido em 4 seções. Na primeira, são discutidas algumas conexões estabelecidas na literatura institucionalista e estruturalista entre salário mínimo e taxa de salário em economias industrializadas e em desenvolvimento, particularmente na economia brasileira. Na segunda seção, a evolução da estrutura do emprego ocorrida na economia brasileira na última década é examinada, identificando alguns mecanismos que contribuíram para a sua maior formalização. $\mathrm{Na}$ terceira discutem-se as relações entre salário mínimo, taxa de salários e estrutura salarial estabelecidas na década e, na quarta seção, algumas conclusões são apresentadas.

\section{Salário mínimo e a taxa de salários}

Embora haja um crescente reconhecimento na literatura contemporânea sobre os efeitos positivos do salário mínimo para a elevação dos baixos salários e 
redução da pobreza (ILO, 2012, Lemos, 2010, Lee; Sobeck, 2012), a influência do salário mínimo institucional sobre a taxa de salários comumente paga aos trabalhadores assalariados não qualificados é de difícil conciliação com a suposição neoclássica de que o salário é determinado pela interação entre uma curva de oferta e uma de procura de trabalho correspondendo, em equilíbrio, à produtividade marginal do trabalho. A definição de um salário institucional acima do preço de equilíbrio representa, nesta perspectiva, uma distorção com resultados negativos sobre o nível de emprego. Entretanto, tanto na tradição dos economistas clássicos como na dos economistas institucionalistas e keynesianos, a influência positiva do salário mínimo sobre os salários e o nível de emprego é amplamente reconhecida. Nesta tradição não há duas curvas inversamente correlacionadas com a taxa de salário e esta, isto é, a taxa de salário paga aos trabalhadores não qualificados e que constituem a maioria dos assalariados ${ }^{1}$, é influenciada pelo poder de barganha destes e pelo estado geral do mercado de trabalho.

A definição de um salário mínimo institucional, isto é, um piso de remuneração abaixo do qual a sociedade considera a remuneração do trabalho insuficiente/injusta para uma vida digna ${ }^{2}$, constitui um caso particular de negociação coletiva para os trabalhadores cujo poder de barganha é estruturalmente débil. Neste sentido, o salário mínimo é essencialmente um salário político. Nas sociedades industrializadas, os preceptores do salário mínimo são historicamente formados por grupos específicos do mercado de trabalho (mulheres, migrantes, jovens) ocupados em atividades específicas na agricultura, pequeno comércio e nos serviços. Neste "mercado de trabalho secundário" (Piore, 1979) onde predominam os baixos salários e alta rotatividade, não há carreiras nem órbitas de comparação. Como a flutuação do estado geral do mercado de trabalho possui alta influência sobre estes salários, o salário mínimo constitui a referência essencial tanto para empregadores e assalariados para a determinação, como para a estabilização da remuneração paga nestas atividades. No "mercado de trabalho primário", isto é, no que se forma entre os assalariados ocupados nas grandes empresas, a determinação salarial é relativamente autônoma às variações do mercado de trabalho e evolui segundo órbitas de comparação e contornos salariais ${ }^{3}$ em que os sindicatos exercem grande influência como unidades de barganha.

(1) "The focus of classical wage theory is the determination of a single rate of remuneration of labour, the natural wage. This calls for an explanation, as observation immediately reveals the existence in the labour market of different pay rates for different occupations. By the term 'natural wage' the classical economists explicitly mean the wages paid to 'common laborers'-i.e. adult male workers without particular qualifications or skills, who are considered to represent the majority of wage earners" (Stiratti, 1991, p. 2).

(2) "...the social minimum is a moral standard. Work bellow that wage is considered an indignity to the person who performs it and exploitation on the part of whomever pays it" (Piore, 1979, p. 202).

(3) "A wage contour is defined as a stable group of wage-determining units (bargain units, plants or firms) which are so linked together by (1) similarity of product markets, (2) resort to similar sources for a labor force, or (3) common labour market organization (custom) that they have common wage-making characteristics" (Dunlop, 1979, p. 66). A principal concorrência nesta economia do trabalho segmentada não é entre salários, mas entre postos de trabalho (que pagam diferentes salários) e a mobilidade ascendente dos trabalhadores do mercado secundário para o mercado primário é a variável chave para a distribuição salarial. 
As transformações nas últimas décadas ocorridas nos EUA ampliaram a importância do papel do salário mínimo. Em condições de desemprego persistente entre os trabalhadores não qualificados e grande declínio dos sindicatos como unidade de barganha, os contornos salariais tornaram-se mais porosos e restritos, e os salários na base do mercado de trabalho ficaram estagnados, abrindo-se o leque salarial. Os empregos típicos do mercado primário diminuíram seu peso relativo no mercado de trabalho e, consequentemente, a importância do salário mínimo na formação do salário não qualificado tornou-se mais relevante para um amplo conjunto de trabalhadores. A sua estagnação relativa constituiu um importante fator de concentração da renda do trabalho ali observada ${ }^{4}$.

Nas sociedades menos desenvolvidas e com grande heterogeneidade e desemprego estrutural como a economia brasileira, o peso do "mercado primário" é muito menor (e certas características observadas na literatura institucionalista do mercado de trabalho circunscrevem-se ao emprego público, possivelmente definindo a nível nacional os maiores contornos salariais entre ocupações) e a maioria da população trabalhadora possui débil poder contratual e baixos salários, inserindo-se em um mercado geral de trabalho amplo e caracterizado por grande rotatividade do emprego.

Um traço notavelmente distinto da segmentação do mercado de trabalho é o peso do assalariamento em atividades mercantis informais e do trabalho autônomo decorrente de estratégias de sobrevivência tanto no mundo rural quanto urbano. Uma parcela grande da população subempregada, embora apareça na população economicamente ativa, não reúne as condições iniciais requeridas de ingresso na base do trabalho não qualificado, neste sentido, a pobreza se confunde com a própria existência do subemprego, não constituindo em nenhum sentido relevante um contingente a ser absorvido com a simples retomada de um nível maior de emprego formal $^{5}$. Entretanto, uma parcela importante da população subempregada encontrase nestas condições e, devido a este excedente estrutural de mão de obra (LEWIS, 1954), os salários pagos na base do mercado tendem para níveis muito baixos ${ }^{6}$.

(4) Card e Krueger (1995) observaram que nos EUA, uma elevação do salário mínimo deslocava o salário médio e reduzia a variância dos salários levando a uma compressão das diferenças na cauda mais baixa da distribuição e redução na desigualdade dos salários. Para uma discussão comparativa, ver Lemos (2010).

(5) Nas economias industrializadas foi exatamente a ação das políticas públicas voltadas à população fora da PEA (educação, saúde e habitação) que tornam empregáveis os indivíduos que procuram emprego no mercado de trabalho. O drama do subdesenvolvimento começa precisamente aqui, a pobreza leva à formação de estratégias de sobrevivência e ocupação de indivíduos que não possuem as condições sociais necessárias a um emprego formal. O aumento relativo deste resulta, assim, de um duplo movimento, o de expansão do nível de emprego decorrente do crescimento da economia e o da provisão de bens públicos que permitam formar trabalhadores empregáveis. Como aqui se argumenta, esses dois movimentos ocorreram simultaneamente na última década.

(6) Há uma longa discussão sobre a influência da hipótese de Lewis (1954) sobre a determinação dos salários na economia brasileira. Em particular, Souza (1979) procura refutá-la sublinhando que esta é autônoma em relação à renda das atividades de subsistência introduzindo, então, a hipótese de que os salários pagos na base do mercado de trabalho são endogenamente formados no núcleo capitalista, no qual o salário mínimo possui uma grande importância. 
Exatamente por isto, a taxa de salário dos trabalhadores regularmente empregados é fortemente influenciada pela evolução do salário mínimo institucional que constitui a principal unidade de barganha salarial para o trabalho de menor qualificação contratado de forma regular.

O nível do salário mínimo e a sua difusão dependem, entretanto, de um conjunto de circunstâncias macroestruturais e institucionais. Com efeito, como o salário mínimo é um salário político e sua maior ou menor efetividade sobre os baixos salários depende não apenas de aspectos institucionais (poder de barganha, fiscalização, etc.), mas também da relação que ele guarda com os outros salários. Isto é, ao lado do seu poder de compra (valor absoluto) é necessário considerar o seu valor relativo. De acordo com Lee e Sobeck (2012) e Belser e Sobeck (2012), os principais parâmetros comparativos são as relações deste salário com o salário médio e o mediano (por exemplo, o salário situado no meio de uma distribuição salarial); um salário mínimo muito baixo ou muito alto em relação à mediana dos salários tem um baixo efeito sobre os baixos salários e, consequentemente, sobre o seu objetivo essencial.

O efeito de um aumento do salário mínimo sobre a folha salarial e os preços depende tanto do número dos trabalhadores diretamente afetados quanto do seu impacto sobre o salário médio. Em relação ao seu impacto sobre os preços deve-se considerar que, em economias com elevado grau de heterogeneidade estrutural, a elevação do salário mínimo no setor privado formal da economia constitui uma desigual pressão sobre os custos entre os setores produtivos. Com efeito, os custos de trabalho são muito distintos segundo o nível de produtividade e os preços relativos. Os aumentos dos salários de base podem se traduzir em aumentos dos preços segundo maior ou menor efeito sobre os custos unitários médios da força de trabalho e da capacidade de fixação dos preços das empresas (mark-up). Eles poderão ser mais ou menos absorvidos por uma redução na parcela dos lucros ou por um menor crescimento dos salários mais altos, neste último caso resultando em uma redução da dispersão salarial (dos salários médios e consequente mudança no padrão salarial) entre trabalhadores segundo a qualificação. Uma vez estabelecido um dado valor absoluto, o seu valor relativo depende da estrutura produtiva e dos padrões predominantes de consumo, mas é possível dizer que há uma sólida relação entre este e a dispersão salarial. A relação entre o nível deste salário e a distribuição salarial foi amplamente discutida e documentada tanto na experiência brasileira do pósguerra quanto em diversos estudos comparativos sobre a distribuição salarial na América Latina ${ }^{7}$.

(7) A compressão dos salários na base da distribuição decorrente de uma elevação do salário mínimo foi observada entre diversos estudos sobre países latino-americanos. Para uma resenha, ver Lemos (2009) e ILO (2012). Um contraste notável entre a elevação dos salários dos trabalhadores não qualificados no Brasil na última década e a estagnação destes observada no México deve-se, precisamente, à evolução do salário mínimo real. 
A suposição de que o salário mínimo forma a taxa de salário na base do mercado geral de trabalho deve esclarecer como este salário se transmite ou influencia a formação dos salários e renda nas atividades e ocupações em que predomina amplo assalariamento informal e um elevado contingente de trabalhadores autônomos sem recursos de qualificação. Souza (1979) observou que, no Brasil, entre 1950 e 1970, a taxa de salários paga na base do trabalho industrial (o núcleo da economia capitalista) constituía um "farol" para as rendas do trabalho precário (isto é, ocupados em organizações não tipicamente capitalistas) ${ }^{8}$. Ao lado da influência do salário mínimo para a formação deste salário, a hipótese principal do farol é posta sobre a renda dos autônomos. Estes correspondem a um amplo universo de empresas familiares, pequenos vendedores de serviços e "trabalhadores por conta própria subordinados", isto é, indivíduos formalmente autônomos mas, a rigor, modernos proletários que recebem por comissão de venda de produtos industriais. Neste último caso, tal como ocorre com os assalariados informais, o mecanismo de transmissão se dá de forma direta. Com efeito, estes trabalhadores, ainda que possuam características específicas (o predomínio do assalariamento informal e feminino no emprego doméstico), compartilham com os trabalhadores formais da mesma realidade social e habitam o mesmo espaço urbano e constituem, de fato, uma reserva de trabalho disponível ao assalariamento formal.

Entretanto, em relação ao trabalho autônomo propriamente dito, o mecanismo é distinto e se transmite, indiretamente, por meio da demanda que os salários de base exercem sobre estas atividades. A renda do trabalho autônomo é, do ponto de vista macroeconômico, uma renda derivada no sentido que aumenta ou diminui conforme a evolução da demanda por estas atividades e do número de prestadores de serviços e de microempresas familiares disputando o mesmo espaço econômico. Uma elevação do salário mínimo age duplamente: por meio do seu efeito sobre a demanda por estes serviços e, dependendo do seu efeito sobre o nível de emprego formal, por meio da redução do número de trabalhadores ocupados nestas atividades. Para distinguir este mecanismo do "efeito farol", vamos denominar este efeito de "efeito propulsão".

Esta análise da estrutura do mercado de trabalho e da influência do salário mínimo descrevia essencialmente o espaço urbano; o mundo rural era, neste período, formado essencialmente por trabalhadores por conta própria, pequenos proprietários e assalariados informais. O salário mínimo escassamente havia chegado ao campo (com a exceção do Sudeste, onde a legislação trabalhista começou a se afirmar nos anos 1960 (Bacha, 1979)), a difusão deste no assalariamento rural nos anos 2000,

(8) "a taxa de salários é um farol que orienta algumas rendas não capitalistas da economia. Neste sentido, o pequeno produtor, o biscateiro, etc., modificam os preços cobrados pelos seus serviços como reação a uma mudança na taxa de salários" (Souza, 1979). Como sublinhado no texto, nossa interpretação sobre a influência do salário mínimo nestas atividades é distinta e se exerce indiretamente por meio de seu efeito na renda e no emprego. 
como será explorada em seções posteriores deste texto, teve grande significado para a maior efetividade do salário mínimo.

Em um trabalho empírico bastante posterior e centrado na PNAD de 1996, Neri, Gonzaga e Camargo (2001) discutiram o "efeito farol" exercido pelo salário mínimo na economia brasileira. Ao examinar a efetividade dos que recebiam exatamente um salário mínimo ou múltiplos dele (neste caso, afirmando-se o salário mínimo como numerário9), o principal resultado destacado neste estudo foi a constatação de que havia uma alta e significativa proporção dos assalariados sem carteira que recebiam o salário mínimo. A proporção destes trabalhadores com renda exatamente equivalente ao mínimo era maior do que no setor formal da economia ${ }^{10}$. Já o efeito do salário mínimo como numerário revelou-se, entretanto, mais relevante entre os assalariados formais.

Neste trabalho (bem como em uma ampla literatura de base econométrica sobre o salário mínimo no Brasil $)^{11}$ não há uma interpretação econômica ou institucional sobre esta constatação empírica, mas sim o reconhecimento em linha com a teoria sobre o farol de que o salário mínimo era seguido como referência básica entre os empregados informais. Em uma versão anterior deste trabalho, na qual esta análise é realizada a nível regional, há, adicionalmente, a constatação de que a prevalência do salário mínimo era maior entre os assalariados formais dos estados do NE (onde o emprego rural e os subempregos rural e urbano são maiores) e entre os assalariados informais do SE. Desse modo, na base do mercado de trabalho, isto é, entre os assalariados de baixos salários predominantes no assalariamento informal no Sudeste e no assalariamento formal no Nordeste, o salário mínimo constituía uma referência central ${ }^{12}$. Como será visto ao longo deste texto, quando se considera não apenas os salários idênticos ao mínimo, mas também os salários próximos ou na vizinhança do mínimo, a referência deste sobre a taxa de salário do trabalho não qualificado é muito mais abrangente. Efeitos de espalhamento e de compressão das diferenças salariais decorrente de um aumento do mínimo foram amplamente reconhecidos, mas não suficientemente explicados de forma articulada com o padrão de crescimento.

(9) Embora a ideia do salário mínimo como numerário constitua uma pista sugestiva para a formação dos salários acima deste valor (como será observado, as categorias costumam fixar os pisos salariais em salários mínimos), ela sugere não haver qualquer relação entre o nível deste salário e a dispersão dos salários. Como será visto, esta relação é muito forte e, à medida que o salário mínimo se eleva, sua função como numerário deixa de existir.

(10) O que levou à seguinte constatação dos autores, "a legislação do salário mínimo é mais efetiva no segmento assalariado ilegal do mercado de trabalho brasileiro do que no segmento assalariado legal" (Neri, Gonzaga, Camargo, 2001).

(11) Lemos (2010)

(12) Em linha com esta constatação também, nos EUA, a maior influência do salário mínimo sobre as remunerações predominantes nas regiões e cidades mais pobres foi amplamente documentada (Lemos, 2010) 
Nas seções seguintes, procuraremos investigar no Brasil da última década a relação de mão dupla entre elevação do salário mínimo e do emprego formal, identificando os efeitos deste salário sobre a taxa de salário por meio de mecanismos diretos institucionais formais e informais e, indiretamente, por meio de seu efeito sobre a demanda por emprego formal.

\section{A evolução da estrutura do emprego e do emprego formal na economia brasileira da última década}

A expansão das exportações, dos salários (em particular do salário mínimo e dos salários próximos a este), o crescimento do crédito e a retomada dos investimentos públicos estiveram entre os principais fatores que levaram ao maior crescimento da economia brasileira observado na segunda metade da década (Serrano, F.; Summa, R., 2012). Este crescimento possuiu, com exceção da agricultura, elevada elasticidade de emprego decorrente, entre outros aspectos da evolução da demanda interna e dos padrões de consumo que se tornaram mais intensivos em serviços, resultando em aumento da ocupação e consequente declínio no desemprego aberto. Este regime de crescimento em que a melhor distribuição de renda e expansão do crédito ampliaram a demanda e o padrão de consumo para novos consumidores de baixos salários levou a uma mudança na estrutura do emprego.

Com efeito, como se pode observar no Quadro 1, ao longo da década, a principal mudança na estrutura das ocupações no país foi o declínio percentual do emprego agrícola (-24,1\% entre 2002 e 2011, mas mais intenso nos anos finais da década), do emprego doméstico, $(-8,0 \%)$ e um declínio relativo do emprego na indústria de transformação (-6,6\%, mas todo ele ocorrido entre 2009 e 2011, decorrente da grande queda da produção industrial em 2010). A construção civil e os serviços, em particular os de "alojamento e alimentação", os de "transporte, armazenagem e comunicação" e "outras atividades", incluindo aqui os serviços financeiros, foram, juntamente com a Administração Pública, os que mais ampliaram sua posição relativa. O emprego na educação e saúde cresceu a taxas mais modestas mantendo-se ao longo do período, mas perdendo posição relativa nos últimos anos. Desse modo, o declínio relativo acentuado da agricultura (em particular entre 2009 e 2011), a manutenção da participação relativa do emprego da indústria de transformação (e declínio, nos dois últimos anos) e a expansão dos serviços mercantis constituem o principal "efeito de composição do emprego". 
Quadro 1

Brasil: mudança na estrutura setorial das ocupações

\begin{tabular}{|c|c|c|c|c|c|c|c|}
\hline & 2002 & 2003 & 2006 & 2009 & 2011 & $\begin{array}{c}\text { Variação } \\
\text { 2002/2011 }\end{array}$ & $\begin{array}{c}\text { Variação } \\
2006 / 2011\end{array}$ \\
\hline $\begin{array}{l}\text { População } \\
\text { Ocupada (em mil } \\
\text { pessoas) }\end{array}$ & 78958 & 80163 & 89318 & 92689 & 93493 & $18,4 \%$ & $4,7 \%$ \\
\hline \multicolumn{8}{|c|}{ Porcentagem de ocupados por setor ${ }^{(1)}$} \\
\hline Agrícola & $21 \%$ & $21 \%$ & $19 \%$ & $17 \%$ & $16 \%$ & $-24,1 \%$ & $-18,7 \%$ \\
\hline Indústria & $14 \%$ & $14 \%$ & $15 \%$ & $15 \%$ & $13 \%$ & $-6,4 \%$ & $-9,7 \%$ \\
\hline $\begin{array}{l}\text { Indústria de } \\
\text { transformação }\end{array}$ & $14 \%$ & $14 \%$ & $14 \%$ & $14 \%$ & $13 \%$ & $-7,1 \%$ & $-9,9 \%$ \\
\hline Construção & $7 \%$ & $7 \%$ & $7 \%$ & $7 \%$ & $8 \%$ & $18,6 \%$ & $27,9 \%$ \\
\hline $\begin{array}{l}\text { Comércio e } \\
\text { reparação }\end{array}$ & $17 \%$ & $18 \%$ & $18 \%$ & $18 \%$ & $18 \%$ & $4,3 \%$ & $1,1 \%$ \\
\hline $\begin{array}{l}\text { Alojamento e } \\
\text { alimentação }\end{array}$ & $4 \%$ & $4 \%$ & $4 \%$ & $4 \%$ & $5 \%$ & $30,8 \%$ & $28,6 \%$ \\
\hline $\begin{array}{l}\text { Transporte, } \\
\text { armazenagem e } \\
\text { comunicação }\end{array}$ & $5 \%$ & $5 \%$ & $5 \%$ & $5 \%$ & $5 \%$ & $17,2 \%$ & $20,1 \%$ \\
\hline $\begin{array}{l}\text { Administração } \\
\text { pública }\end{array}$ & $5 \%$ & $5 \%$ & $5 \%$ & $5 \%$ & $5 \%$ & $11,7 \%$ & $9,0 \%$ \\
\hline $\begin{array}{l}\text { Educação, } \\
\text { saúde e serviços } \\
\text { sociais }\end{array}$ & $9 \%$ & $9 \%$ & $9 \%$ & $9 \%$ & $9 \%$ & $3,4 \%$ & $2,8 \%$ \\
\hline $\begin{array}{c}\text { Serviços } \\
\text { domésticos }\end{array}$ & $8 \%$ & $8 \%$ & $8 \%$ & $8 \%$ & $7 \%$ & $-9,2 \%$ & $-6,3 \%$ \\
\hline $\begin{array}{l}\text { Outros } \\
\text { serviços } \\
\text { coletivos, sociais } \\
\text { e pessoais }\end{array}$ & $4 \%$ & $4 \%$ & $4 \%$ & $4 \%$ & $4 \%$ & $-3,1 \%$ & $-11,1 \%$ \\
\hline $\begin{array}{c}\text { Outras } \\
\text { atividades }\end{array}$ & $7 \%$ & $7 \%$ & $7 \%$ & $8 \%$ & $9 \%$ & $30,7 \%$ & $19,3 \%$ \\
\hline $\begin{array}{l}\text { Atividades mal } \\
\text { definidas }\end{array}$ & $0 \%$ & $0 \%$ & $0 \%$ & $0 \%$ & $0 \%$ & $-52,7 \%$ & $-43,0 \%$ \\
\hline Total & $100 \%$ & $100 \%$ & $100 \%$ & $100 \%$ & $100 \%$ & - & - \\
\hline
\end{tabular}

(1) Simplificação dos setores da CNAE utilizada pela PNAD para classificar as ocupações. A correspondência entre os setores da CNAE e os setores aqui utilizados está descrita no anexo estatístico das publicações anuais da PNAD (2002-2011, IBGE).

Fonte: PNAD, IBGE. 
Mais notável por sua intensidade foi a mudança na estrutura institucional do mercado de trabalho. Com efeito, uma transformação crucial ocorrida na última década foi o crescimento do assalariamento que se deu a uma taxa muito superior à do crescimento observado na população ocupada. Este crescimento se deu exclusivamente por meio do contrato formal de trabalho e o assalariamento informal manteve-se estagnado em termos absolutos levando a um acentuado declínio relativo. Ao lado deste, houve uma queda acentuada absoluta e relativa do trabalho não remunerado (uma consequência da redução da ocupação rural, das transferências de renda, bem como da modernização da agricultura), um baixo crescimento do trabalho doméstico informal e relativamente baixo crescimento do trabalho por conta própria. É importante destacar que, entre 2009 e 2011, um período de grande desaceleração da produção industrial e de aumento do desemprego, o processo de assalariamento formal continuou em níveis elevados decorrente da expansão integralmente explicada pelo emprego nos serviços. Ver Gráfico 1.

\section{Gráfico 1}

Participação dos trabalhadores formais no total ${ }^{(1)}$

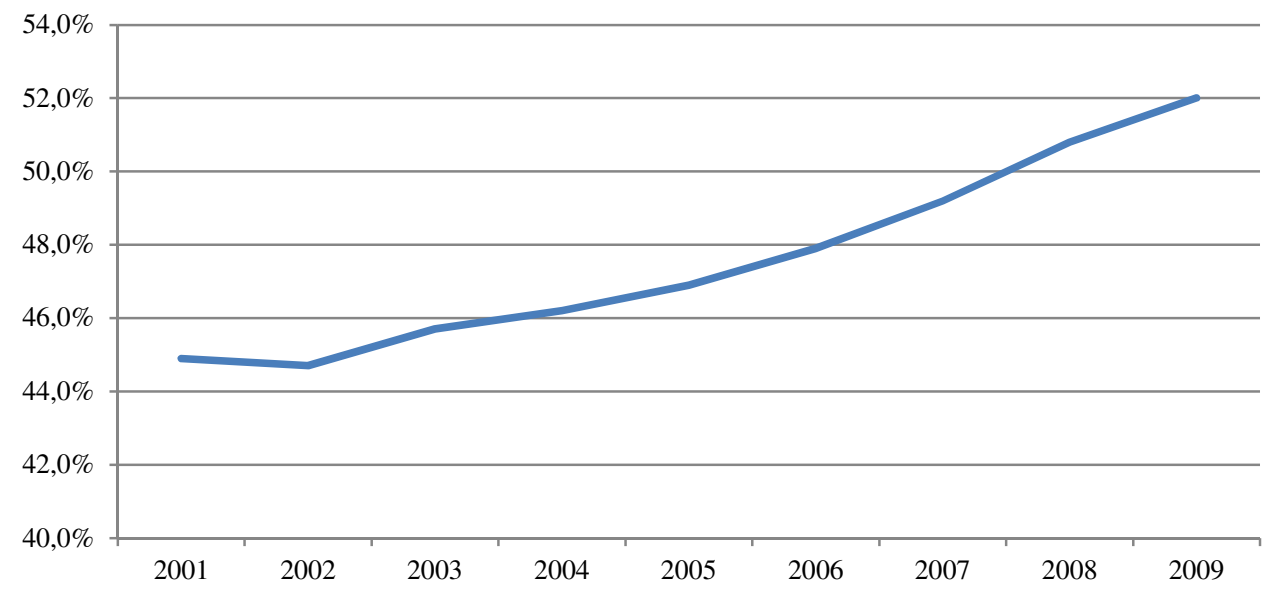

(1) Empregados com carteira/ Total de Empregados + Trabalhadores por Conta Própria (o complemento do Grau de Informalidade - Definição I do IBGE)

Fonte: Ipeadata.

Embora os níveis de ocupação precária e de baixa renda sejam muito mais elevados no Nordeste do que no restante do país - historicamente, as proporções dos trabalhos agrícola, doméstico, autônomo precário e sem remuneração são muito maiores do que no Sudeste - também houve, nesta região, uma substancial redução destas ocupações. Com efeito, em 2001, os empregados assalariados correspondiam a $43 \%$ dos ocupados e, destes, apenas $37,9 \%$ eram assalariados formais; em 2005 , $50,9 \%$ dos ocupados eram assalariados e, destes, 36,5\% eram formais; em 2009, $56 \%$ 
dos ocupados eram assalariados e, destes, 40,1\% eram formais; em 2011, os assalariados perfaziam 58\% dos ocupados nordestinos e, destes, $44 \%$ possuíam carteira de trabalho. Assim, ao longo de uma década, o emprego formal no NE aumentou quase 10pp. Desse modo, a redução da ocupação agrícola em atividades de subsistência, particularmente intensa no Nordeste, teve um poderoso efeito para a redução global do subemprego.

Esta transformação essencial - redução do emprego precário e aumento do emprego assalariado formal - se acentuou na segunda metade da década, mas já estava em curso desde o seu início. Desse modo, além das mudanças na estrutura produtiva a favor das atividades com maior elasticidade emprego-produto, houve uma elevada expansão do emprego assalariado formal e consequente declínio relativo das outras formas de ocupação. A formalização do emprego na última década pode ser explicada pela interação de diversos processos econômicos e institucionais. No plano econômico, tal como se observou, o principal movimento foi o aumento da demanda global decorrente do aumento do consumo interno, particularmente estimulado pelo aumento do salário mínimo e das transferências sociais. Ao lado deste, ocorreram mudanças nos padrões de consumo associadas tanto ao aumento de renda quanto à difusão do crédito. Houve um deslocamento do consumo para bens e serviços regularmente oferecidos nos estabelecimentos mercantis, o que levou a um aumento do emprego nos estabelecimentos maiores. No plano social, as políticas de renda ampliaram as possibilidades de emprego formal (socialização positiva do indivíduo), diminuindo o número daqueles compulsoriamente ocupados em estratégias de sobrevivência (em particular no Nordeste e nas atividades agrícolas). Por outro lado, aumentou a fiscalização do mercado de trabalho tanto urbano quanto rural e criaram-se mecanismos favorecedores da formalização da pequena empresa e, por fim, com o mercado de trabalho aquecido, os trabalhadores passaram a demandar maior formalização devido aos salários indiretos associados à carteira e, sobretudo como via de acesso ao crédito. A conjugação de todos estes fatores na década explica esta mudança estrutural $^{13}$. No restante desta seção, discutem-se algumas qualificações e evidências.

(13) "This significant expansion of formal employment - which began after the devaluation of the Brazilian currency and was intensified by the increased pace of economic growth in the period 2004-2008 - was a result of two different effects: on the one hand, a tendency towards formalization of businesses and labour contracts; on the other, an increase in the number of formal jobs generated by every percentage point of GDP growth. Thus, the process of increase in formal employment was very strong, due to modifications and expansion of the Brazilian productive structure, but also due to the formalization of contracts through the supervision conducted by the Ministry of Labour and Employment" (Baltar et al., 2010, p. 17). 


\section{Redução da pobreza}

Como se observou, parte da população registrada como ocupada na PNAD não possui as características sociais e de qualificação básica (idade, escolarização, habitação) que habilitam os indivíduos a participarem da base do mercado geral de trabalho formal mesmo naquelas atividades de menor qualificação. A inserção de menores nas atividades informais, nas atividades sem remuneração, no trabalho eventual e nas atividades ilegais constitui simples estratégia de sobrevivência impelida pela pobreza. Ainda que difundidas em todo o país, estas atividades se concentram no Nordeste e no mundo rural (circundado por aglomerações urbanas empobrecidas). Desse modo, a redução desta, por meio de políticas de renda (tais como o bolsa família e aquelas vinculadas ao salário mínimo, à aposentadoria rural e a transferências como o $\operatorname{LOAS}^{14}$ ) e outras ações visando a massificação da escolarização resultaram em uma redução desta integração forçada no subemprego e, consequentemente, no peso destas ocupações na ocupação total. Um simples exemplo desta mudança pode ser inferido pelo trabalho do menor. De acordo com os dados da PNAD, em 2005 existiam 5147 mil trabalhadores (homens e mulheres) ocupados com idade entre 10 e 17 anos; em 2011, este número caiu para 3584 mil. Considerando agora a participação no emprego total das pessoas sem instrução em conjunto com as com aquelas com apenas 1 a 3 anos de instrução, observa-se que a participação destes indivíduos no emprego total caiu de 21,1\% em 2005 para 15,8\% em 2011. Se o bolsa família manteve menores fora da força de trabalho, o maior poder de compra do salário mínimo reteve os idosos e aposentados contribuindo para reduzir o subemprego. Deste modo, em que pesa o elevado grau de pobreza e o predomínio dos baixos salários que distinguem a sociedade brasileira, a redução desta por meio de ações sobre os grupos fora da PEA melhorou as condições gerais para uma inserção menos precária na PEA.

\section{Mudanças nos padrões de consumo e a demanda dos trabalhadores}

Historicamente, os baixos salários levaram o mundo urbano à proliferação de atividades (como a autoconstrução) e à demanda por produtos e serviços baratos e de segunda mão oferecidos em condições precárias, informais e irregulares. A demanda por estes bens e serviços decorre dos baixos salários. Desse modo, a simples elevação do poder de compra dos salários gera um deslocamento relativo na demanda por bens e serviços na direção daqueles providos de forma regular, em contratos formalizados ${ }^{15}$. Este deslocamento torna-se ainda maior quando, simultaneamente, ocorre um deslocamento dos padrões de consumo. A elevação do salário real na base do assalariamento e o acesso ao crédito ao consumo se traduziram

(14) Em 2009, cerca de 14447 mil aposentados recebiam exatamente um salário mínimo e 3411 mil receberam transferências sociais via LOAS (Barbosa de Melo et al., 2012).

(15) Ver próxima seção. 
em uma evolução do padrão de consumo em que as demandas - por alimentos industrializados, pela alimentação fora do lar, por serviços, educação, saúde e por toda a família de bens duráveis de consumo - cresceram intensamente entre os assalariados. Um corolário desta transformação foi o deslocamento relativo ainda maior do que o decorrente da simples elevação da renda da demanda sobre bens baratos de qualidade inferior (na alimentação, no vestuário e nos bens duráveis usados) oferecida em organizações não tipicamente capitalistas (pequena produção agrícola, empresas familiares no comércio e na indústria) ou à margem de qualquer regulação (biscateiros, pequenos vendedores de serviços), pela demanda por bens e serviços produzidos nas empresas capitalistas (em particular na agricultura, no comércio e serviços tanto nas regiões metropolitanas quanto nas cidades não metropolitanas) levando, consequentemente, ao aumento do emprego assalariado formal. Os supermercados, os shoppings centers, as grandes redes de comércio foram os principais difusores dos novos bens. A difusão do crédito ao consumo, do uso de cartões de crédito, isto é, do dinheiro de crédito e a formalização do trabalho, constitui um processo de mão dupla. Este mesmo movimento ocorreu com a produção industrial de casas populares.

Tendo em vista o conjunto de direitos contratuais associados ao assalariamento formal (como o $13^{\circ}$ salário, o acesso ao FGTS, o direito ao repouso semanal e a férias remuneradas e o acesso a subsídios ao transporte e a alimentação), a posse da carteira de trabalho configura uma posição na ocupação e um salário indireto que transcende o diferencial de remuneração observado nas pesquisas domiciliares. Fundamentalmente, o acesso ao "moderno" estilo de vida urbano passou a ser crescentemente mediado pelo crédito entre os trabalhadores de base. Ao lado dos direitos contratuais, a carteira de trabalho habilita ao seu possuidor um comprovante de rendimentos essencial para o acesso ao crédito, cujo barateamento e expansão foram notáveis na década. Desse modo, a aceitação por parte do trabalhador pobre e sem recursos de qualificação de um contrato informal ou a busca de formas de sobrevivência em atividades precárias do trabalho autônomo como forma de trabalho principal não é uma opção (com exceção de casos muito particulares), mas decorre de uma imposição do desemprego estrutural e do baixo poder de negociação de um amplo grupo de trabalhadores, especialmente das mulheres e dos jovens, em atividades como a agricultura, a construção civil, o trabalho doméstico e nas atividades de serviços ${ }^{16}$. Com o mercado de trabalho aquecido, os trabalhadores nestas "posições ocupacionais de baixos salários" conseguiram ou se deslocar para outras atividades em que é maior o grau de formalização ou conseguiram um contrato formal dos empregadores (um exemplo eloquente se deu com o emprego doméstico). Como será visto na sequência deste

(16) Isto se traduz por uma elevada taxa de rotatividade no trabalho assalariado, especialmente alta na construção civil, agricultura e comércio. 
texto, a principal órbita de comparação e negociação para o estabelecimento da remuneração do trabalho nestas atividades é o salário mínimo nacional.

\section{Tamanho dos estabelecimentos urbanos}

Com base nos dados da RAIS relativos ao período entre 1995-1999 e entre 2003-2007, Corseuil, Moura, e Ramos (1999) examinaram a expansão do assalariamento formal e contrastaram a influência da criação de novos estabelecimentos (vínculos formais) e do aumento do tamanho médio do estabelecimento observado entre os períodos. Observaram que, embora a maior parte dos postos de trabalho formais tenha se dado pelo aumento do número de estabelecimentos com emprego formal, a principal mudança entre os dois períodos foi o aumento no tamanho do estabelecimento médio ${ }^{17}$. Os estabelecimentos criados na última década foram de tamanho relativo maior. Embora estas transformações possam ter se manifestado também na segunda metade dos anos 2000, a principal transformação do emprego assalariado segundo o tamanho do estabelecimento como se depreende das estatísticas do cadastro de empresas do IBGE (Quadro 2), foi a

Quadro 2

Brasil: assalariados segundo o tamanho do estabelecimento

\begin{tabular}{|l|c|c|c|}
\hline & 2002 & 2006 & 2009 \\
\hline $\begin{array}{l}\text { Total de assalariados } \\
\text { (em 1000 pessoas) }\end{array}$ & $27855(100 \%)$ & $34167(100 \%)$ & $40212(100 \%)$ \\
\hline De 0 a 9 empregados & $3386(12,1 \%)$ & $4097(12,0 \%)$ & $5249(13,0 \%)$ \\
\hline $\begin{array}{l}\text { De 10 a 49 } \\
\text { empregados }\end{array}$ & $5016(18,0 \%)$ & $6181(18,0 \%)$ & $8721(21,7 \%)$ \\
\hline $\begin{array}{l}\text { De 50 a 99 } \\
\text { empregados }\end{array}$ & $1856(6,6 \%)$ & $2227(6,5 \%)$ & $3355(8,3 \%)$ \\
\hline $\begin{array}{l}\text { De 100 a 499 } \\
\text { empregados }\end{array}$ & $12708(45,6 \%)$ & $15937(46,6 \%)$ & $14975(37,2 \%)$ \\
\hline $\begin{array}{l}\text { Acima de 500 } \\
\text { empregados }\end{array}$ & $5721(16,7 \%)$ & $7908(19,6 \%)$ \\
\hline
\end{tabular}

Fonte IBGE: Estatísticas do Cadastro Central de Empresas.

redução do emprego nas unidades com mais de 500 assalariados (essencialmente concentradas na indústria de transformação) e uma forte expansão do emprego na empresa média, especialmente daquela entre 100 a 499 assalariados. Por outro lado, como documenta o Anuário da Microempresa (Sebrae), houve uma maior expansão

(17) “A decomposição para os subperíodos mencionados denota que a melhora no desempenho do emprego formal de 2003-2007 em relação a 1995-1999 deve-se quase que exclusivamente a uma mudança drástica no efeito do tamanho médio dos estabelecimentos. Enquanto a taxa de crescimento do emprego devido ao efeito quantidade de estabelecimentos difere apenas em três pontos percentuais (p.p.) entre os dois subperíodos, a taxa de crescimento do emprego devido à variação do tamanho médio passa de $-12,8 \%$ para $+8,3 \%$, diferença de mais de 20 p.p." (Corseuil; Moura; Ramos, 1999). 
destas empresas no setor de serviços e declínio relativo no comércio e indústria. Esta transformação, essencialmente induzida pelo crescimento maior do emprego assalariado formal nos serviços e no comércio altera muito pouco a composição do emprego assalariado formal, mas possui, como será visto na próxima seção, importante impacto sobre a distribuição salarial.

Este deslocamento na composição do emprego assalariado deve ser considerado conjuntamente com a maior formalização do emprego das pequenas empresas.

\section{Tributação e Fiscalização ${ }^{18}$}

A adoção de um regime tributário simplificado para micro e pequenas empresas (Simples) - embora tenha sido criado em 1996 - teve sua cobertura ampliada na última década, aumentou os incentivos para a formalização que cresceu a taxas elevadas nos novos estabelecimentos optantes (ainda que em um ritmo inferior ao da formalização nas empresas maiores não optantes). Inclui-se entre estes o acesso ao sistema de crédito e às compras governamentais (Cardoso Jr., 2009, Baltar et al., 2010).

Em geral, a informalização do trabalho constitui uma forma particular de evasão de impostos. Neste sentido, outra mudança institucional com importante impacto sobre os níveis de formalização foi a maior fiscalização do Ministério do Trabalho ocorrida na década tanto sobre o trabalho urbano quanto sobre o trabalho rural $^{19}$. A maior pressão de arrecadação fiscal do Governo, desde 1999, teve como corolário um maior envolvimento do Ministério do Trabalho no controle das pequenas empresas e nas brechas abertas pelo processo de terciarização. ${ }^{20}$ Embora este movimento tenha sido mais intenso nas cidades, ele afirmou-se expressivo na área rural, aumentando substancialmente o número de trabalhadores registrados e

(18) "the impact and usefulness of a minimum wage policy depends on whether minimum wages are paid. This, in turn, depends on the effectiveness of the enforcement mechanism. Penalties for violators, adequate compensation for workers whose rights have been breached, and suitable resourcing of the enforcement authority, are all crucial factors. But the active involvement of social partners in both the design and operation of minimum wage enforcement regimes is essential to enhance their impact" (ILO, 2009, p. 10).

(19) "The contribution of the inspection system can be seen in the significant increase in formal jobs each year, rising from 250,000 in 1999 to 746,000 in 2007. Considering the size of the labour market, those numbers are not so high, but the exemplary effect should also be taken into account - when there are signs of increased surveillance, companies preemptively adjust to the law in order to avoid being fined" (Baltar et al., 2010, p. 24).

(20) "companies that outsource services have been held accountable when the contractor does not comply with labour laws. The recognition of accountability, or at least subsidiary accountability, induced many companies to adopt preventive measures in order to avoid the accumulation of future labour liabilities. That is, contractor firms became subject to monitoring by the outsourcing company. For example, formalization in sectors with highly outsourced services, such as private security, cleaning and maintenance, rose above the average level of formalization of the labour market" (Baltar et al., 2010, p. 26). 
formalizados $^{21}$. Com efeito, segundo o Anuário Rural (MT-Dieese, com base na PNAD), a proporção dos ocupados na agricultura filiados a sindicatos (25\%) era superior à proporção observada na indústria $(21,2 \%)$ em 2009.

\section{Salário mínimo, taxa de salários e estrutura salarial}

A recuperação do poder de compra do salário mínimo constitui, possivelmente, o principal fator distributivo da renda do trabalho na economia brasileira recente. Ela resultou de uma ação coletiva das centrais sindicais ao longo da década e de um acordo com o governo estabelecendo, desde 2005, uma política explícita de valorização do salário mínimo, institucionalizada em 2007 e baseada no ajuste anual do salário mínimo segundo a inflação somada à taxa média de crescimento real do PIB observada nos dois anos anteriores ${ }^{22}$. Entre 2000 e 2011, o salário mínimo real praticamente dobrou de valor, mas foi entre 2006 e 2010 que as maiores altas ocorreram. (Ver Gráfico 2)

\section{Gráfico 2}

Evolução do Salário Mínimo Real ${ }^{(1)}$

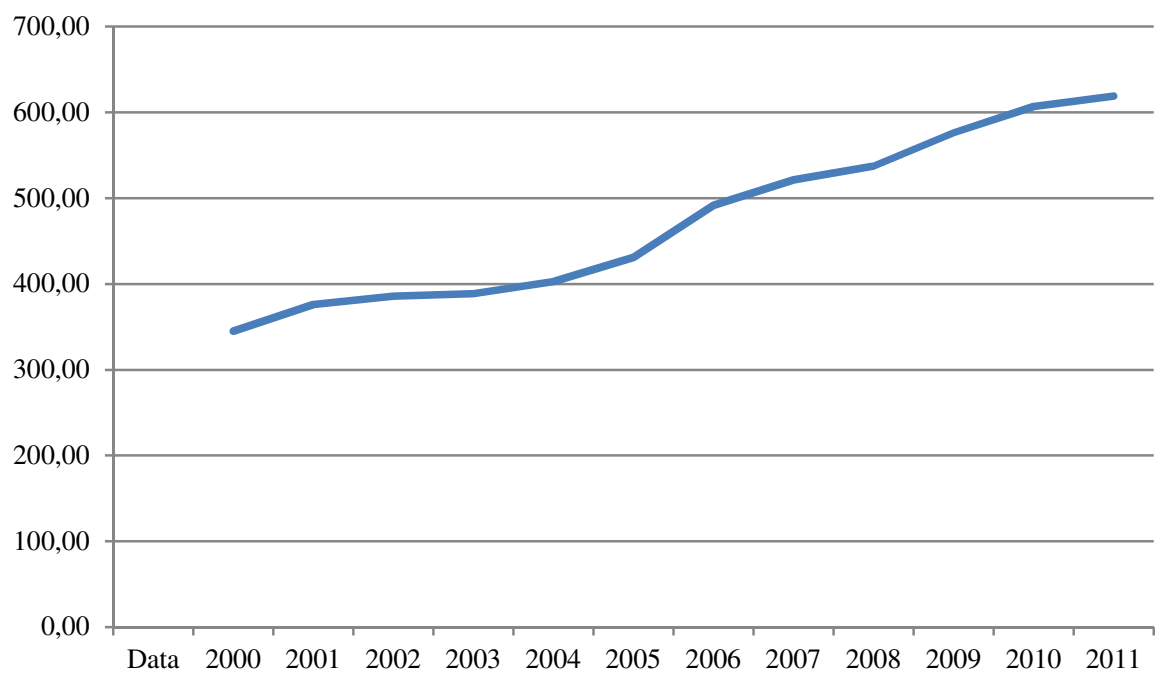

(1) Valor real, deflacionado pelo IPCA com base em 2000.

Fonte: Ipeadata

(21) De acordo os dados do Ministério do Trabalho e elaborados pelo Dieese, se em 1999 foram identificados, pelos fiscais, 24990 trabalhadores informais e imediatamente formalizados, em 2005 este número pulou para 115.560. O risco para as empresas de contratação de emprego informal aumentou.

(22) De acordo com Barbosa de Melo et al. (2012), embora esta política vise aumentar o valor do salário mínimo até 2023, o mecanismo previsto de ajuste deverá ser negociado no final do governo atual. 
Elementos macroestruturais e a mudança dos preços relativos (ver Serrano; Suma, 2012) viabilizaram este aumento sem que este tivesse efeito maior sobre a taxa de inflação. Discute-se a seguir o valor absoluto e relativo do salário mínimo e algumas transformações sobre a estrutura salarial.

\section{Salário mínimo e a estrutura salarial}

A despeito da grande recuperação do poder de compra do salário mínimo oficial, a distancia entre este e o "salário mínimo social" - isto é, o salário mínimo que corresponda a um nível de consumo considerado socialmente necessário para o trabalhador e sua família - permanece muito alta, ainda que em declínio. Esta distancia, isto é, o baixo nível absoluto do salário mínimo no país, se deve ao seu persistente declínio desde 1955 e, sobretudo, de sua queda pronunciada entre 1980 e 1994. Ao longo deste período em que o salário mínimo real teve o seu poder de compra reduzido ou estagnado, novos bens, novos serviços e hábitos de consumo foram difundidos, tornando este salário pouco representativo e fazendo do trabalhador sem recursos de qualificação um trabalhador essencialmente pobre ${ }^{23}$.

Internacionalmente, de acordo com Global Wage Report da ILO (2009), o salário mínimo brasileiro registrado no final da década situava-se exatamente em uma posição intermediária (pouco acima de \$250 em paridade do poder de compra e em média semelhante com a registrada na América Latina) e em relação à renda per capita, o salário mínimo no país, a despeito do crescimento observado na década, situava-se abaixo da média (aproximadamente $30 \%$ ) $^{24}$. Do ponto de vista relativo, os baixos salários são considerados na literatura comparativa internacional (ILO, 2012) como aqueles inferiores a $2 / 3$ do salário mediano horário mensal. Tendo em vista a grande segmentação da estrutura salarial e de rendimentos brasileira, é sempre arbitrário definir o universo de comparação. Se considerarmos o rendimento das regiões metropolitanas (PME, IBGE), infere-se que em 2009 o salário mediano nas regiões metropolitanas brasileira situava-se em torno de $\mathrm{R} \$ 700,00$ e, como o salário mínimo era $\mathrm{R} \$ 460,00$, ele situava-se próximo ao nível abaixo do qual predominam os baixos salários (Fonte; Pero; Berg, 2012). Se considerarmos, com base no relatório da ILO, um salário mínimo situado em torno de $40 \%$ do salário médio como um valor usual (Belser; Sobeck, 2012), observa-se que o salário mínimo brasileiro começou a se aproximar desta relação apenas em $2011^{25}$.

(23) Se usarmos o salário necessário do DIEESE como proxy deste valor social, observa-se que, em 2005, este salário mínimo necessário correspondia a 5,29 salários mínimos oficiais; em 2011, este número havia caído para 4,17 .

(24) Este percentual era de apenas 13,4 em 2001 evoluindo para 21,1 em 2006 e atingindo a 28,7 em 2011. Com base nas contas nacionais trimestrais utilizando-se o PIB a preços de 2010. Elaboração do IPEA, Ipea Data.

(25) Naturalmente, estes valores são muito arbitrários. Adicionalmente, deve-se observar que a unidade comparativa é o salário mínimo (e salário médio por hora). Como, em geral, as estatísticas são mensais as comparações são derivações a partir de uma imputada jornada media. Desse modo, as referências comparativas devem ser usadas com cautela e apenas como uma aproximação. 
Ao longo da década, o salário mínimo cresceu relativamente mais do que o salário mediano e ambos aumentaram mais do que o aumento registrado no salário médio, levando a uma redução relativa da dispersão salarial ao mesmo tempo em que crescia a massa dos salários ${ }^{26}$. Como se constata no Quadro 3, devido à queda do subemprego, houve, entre 2006-2011, substancial redução das posições ocupacionais com rendimento inferior a $1 \mathrm{SM}$. Se considerada de forma agregada, a massa dos trabalhadores brasileiros (independente da posição na ocupação) recebeu, na década, salários próximos ao salário mínimo e foram as posições ocupacionais com renda de até dois salários mínimos que responderam pela vasta maioria dos empregos criados.

Quadro 3

Proporção das pessoas ocupadas por classe de rendimento médio no trabalho principal - Brasil

\begin{tabular}{|l|c|c|c|c|c|c|c|}
\hline & 2001 & 2003 & 2006 & 2009 & 2011 & $\begin{array}{c}\text { Variação } \\
2001 / 2011\end{array}$ & $\begin{array}{c}\text { Variação } \\
2006 / 2011\end{array}$ \\
\hline Até $1 / 2$ SM & $9,2 \%$ & $11,9 \%$ & $11,6 \%$ & $11,2 \%$ & $8,3 \%$ & $-10,0 \%$ & $-28,6 \%$ \\
\hline Mais de 1/2 a SM & $19,1 \%$ & $20,7 \%$ & $24,5 \%$ & $22,5 \%$ & $21,6 \%$ & $12,9 \%$ & $-12,1 \%$ \\
\hline Até 1SM & $28,3 \%$ & $32,6 \%$ & $36,1 \%$ & $33,7 \%$ & $29,9 \%$ & $5,6 \%$ & $-17,1 \%$ \\
\hline Mais de 1 a 2 SM & $30,1 \%$ & $30,0 \%$ & $33,9 \%$ & $36,1 \%$ & $37,3 \%$ & $23,9 \%$ & $10,0 \%$ \\
\hline Mais de 2 a 3 SM & $14,9 \%$ & $14,8 \%$ & $11,9 \%$ & $11,9 \%$ & $14,9 \%$ & $0,1 \%$ & $25,4 \%$ \\
\hline Mais de 3 a 5 SM & $12,5 \%$ & $11,6 \%$ & $8,2 \%$ & $10,0 \%$ & $9,0 \%$ & $-28,1 \%$ & $9,5 \%$ \\
\hline Mais de 5 a 10 SM & $8,8 \%$ & $6,7 \%$ & $6,9 \%$ & $5,6 \%$ & $6,3 \%$ & $-29,1 \%$ & $-9,0 \%$ \\
\hline Mais de 10 a 20 SM & $3,8 \%$ & $3,0 \%$ & $2,3 \%$ & $2,2 \%$ & $2,1 \%$ & $-46,5 \%$ & $-8,9 \%$ \\
\hline Mais de 20 SM & $1,6 \%$ & $1,4 \%$ & $0,8 \%$ & $0,7 \%$ & $0,7 \%$ & $-57,3 \%$ & $-13,0 \%$ \\
\hline Total & $100 \%$ & $100 \%$ & $100 \%$ & $100 \%$ & $100 \%$ & & \\
\hline
\end{tabular}

Fonte: PNAD, IBGE.

Como a dispersão salarial e de renda é muito alta na economia brasileira e os cortes por posições ocupacionais agregam realidades muito distintas, é importante considerar a evolução do salário mediano por posições sócio-ocupacionais mais homogêneas. A partir dos dados da PNAD, Horta Barbosa (2012) estimou os salários medianos dos trabalhadores tipicamente urbanos (excluindo os trabalhadores qualificados e posições gerenciais), dos trabalhadores domésticos e dos autônomos (excluindo os profissionais liberais e os qualificados) (Ver Quadro 4). Este mesmo exercício foi feito para os trabalhadores rurais, discriminando os trabalhadores assalariados, os autônomos e os proprietários por conta própria (Ver Quadro 5).

(26) Este resultado deve ser contrastado com o que ocorreu nos anos 1990. Segundo estimativa de Baltar et al. (2010), em 2003, o salário mínimo era 9,7\% superior ao salário de 1998, mas a renda média dos 50\% mais pobres caiu $8,5 \%$ entre estes anos. 
Quadro 4

Evolução da mediana dos rendimentos dos trabalhadores tipicamente urbanos (R\$) e em relação ao salário mínimo

\begin{tabular}{|l|c|c|c|c|}
\hline & 2002 & 2005 & 2009 & Tx Crescimento \\
\hline Autônomos & 300,00 & 350,00 & 500,00 & $67 \%$ \\
\hline Assalariados & 320,00 & 434,00 & 600,00 & $88 \%$ \\
\hline Domésticos & 200,00 & 300,00 & 450,00 & $125 \%$ \\
\hline Salário Mínimo & 195,00 & 286,00 & 460,00 & $135 \%$ \\
\hline
\end{tabular}

Fonte: Horta Barbosa (2012) a partir micro dados da PNAD.

Quadro 5

Evolução da mediana dos rendimentos (todas as fontes) dos trabalhadores agrícolas e em relação ao salário mínimo

\begin{tabular}{|l|c|c|c|c|}
\hline & 2002 & 2005 & 2009 & Tx de Crescimento \\
\hline $\begin{array}{l}\text { Proprietários por } \\
\text { conta própria }\end{array}$ & 233,00 & 320,00 & 500,00 & $115 \%$ \\
\hline Autônomos & 150,00 & 215,00 & 320,00 & $113 \%$ \\
\hline Assalariados & 200,00 & 300,00 & 465,00 & $133 \%$ \\
\hline Salário Mínimo & 195,00 & 286,00 & 460,00 & $135 \%$ \\
\hline
\end{tabular}

Fonte: Horta Barbosa (2012) a partir micro dados da PNAD

Depreende-se destes dados uma liderança do crescimento do salário mínimo em relação ao salário mediano e o do rendimento mediano dos trabalhadores não qualificados tanto no meio urbano quanto no meio rural. No início da década, o salário mínimo era baixo em relação ao salário mediano urbano, mas aumentou proporcionalmente em relação a este. Os rendimentos medianos mais baixos, isto é, os dos trabalhadores domésticos e os dos assalariados rurais, aumentaram mais do que os demais e foram arrastados essencialmente pelo maior crescimento do salário mínimo. Houve uma convergência maior entre o salário médio e mediano dos empregados com carteira e o salário dos empregados sem carteira e os ocupados por conta própria, justamente a base da pirâmide distributiva. Ou seja, não apenas estas ocupações reduziram-se relativamente, mas os que permaneceram nestas posições obtiveram um crescimento em suas rendas maior do que o crescimento médio dos empregados formais. Estas transformações ocorreram devido tanto ao "efeito farol" quanto ao "efeito propulsão", anteriormente mencionados.

Empiricamente, diversos trabalhos recentes convergem para este ponto a partir de diferentes metodologias. Com base nos dados da PNAD, Sabóia (2010) examinou as elasticidades dos rendimentos do trabalho em relação ao salário mínimo entre 1995 e 2006, um período distinto do aqui examinado, mas que incorpora algumas das transformações discutidas, e encontrou um amplo apoio para o "efeito 
farol", "cuja luz vai se apagando na medida em que se afasta para baixo e para cima do seu valor" (Sabóia, 2010, p. 3) 27.

Desse modo, nesta década, o aumento do salário mínimo real foi importante não apenas para os assalariados diretamente contratados a este valor ${ }^{28}$ e para a elevação do nível dos baixos salários e rendas dos trabalhadores assalariados informais e rendas do trabalho autônomo, mas também para os empregados com salários um pouco mais altos e, consequentemente, para a taxa de salários urbana. Ou seja, este adensamento da base salarial em torno do mínimo se combinou com a afirmação cada vez maior do salário mínimo em relação à taxa de salário no setor moderno da economia.

Visto de qualquer perspectiva de agregação das ocupações, o salário mínimo se aproximou do salário médio. Tal aproximação decorreu de ter havido um maior crescimento do primeiro em relação ao crescimento do último. Em 2002, o salário mínimo correspondia a $26 \%$ do salário habitual médio nas principais regiões metropolitanas e, em 2011, a proporção era de 36\% (Ver Quadro 6).

Considerando a evolução dos salários entre setores e atividade, observa-se um declínio geral do salário médio em relação ao salário mínimo ${ }^{29}$ com exceção da indústria de extração, onde o salário médio não apenas elevou-se em termos do mínimo (seguramente influenciado pelo setor de petróleo), mas também se afirmou como o setor de maior salário médio, superior ao das atividades financeiras e dos serviços de utilidade pública (com exceção dos de eletricidade e gás) que detinham os salários médios mais altos. Em particular, destaca-se a queda do salário médio em relação ao salário mínimo na indústria de transformação (ver Quadro 7). Os salários médios na indústria de transformação tanto em setores mais dinâmicos e menos intensivos em mão de obra quanto nos setores mais intensivos em mão de obra (como

(27) "Defende-se que o SM teve um papel importante na determinação dos níveis de renda para aqueles que recebem valores próximos do SM, especialmente no setor formal da economia. O argumento é também o de que, embora tenha aumentado a parcela de pessoas ocupadas recebendo menos de $1 \mathrm{SM}$, mesmo aqueles que "ficaram um pouco para trás" foram, de alguma forma, beneficiados pelo crescimento do SM real, que teria sido transferido parcialmente para níveis mais baixos de remuneração. Isso ocorreu também para níveis um pouco superiores ao valor do SM. Portanto, o SM teria funcionado como uma espécie de "farol" para os níveis relativamente baixos de rendimento do trabalho, cuja luz vai se apagando à medida que se afasta para baixo e para cima de seu valor. Assim, para os níveis extremamente baixos de rendimentos encontrados no setor informal, a influência do SM é muito pequena. "Da mesma forma, seu efeito sobre os altos rendimentos tem sido nulo, quando não negativo" (Sabóia, 2010, p. 3). Na mesma direção, destacaram Fontes, Pero e Berg (2012). Nestes, como na maioria dos estudos empíricos, não se distinguem os dois mecanismos examinados no texto e ambos são referidos ao efeito farol.

(28) Em 2009, com base nos dados da PNAD, 4409 mil assalariados no setor formal, 2138 mil trabalhadores informais, 1443 mil trabalhadores domésticos e 859 mil trabalhadores autônomos ganhavam exatamente um salário mínimo (Barbosa de Melo et al., 2012).

(29) Deve-se observar que esta configura uma realidade distinta do que se passou na segunda metade dos anos 1990, quando o salário mínimo real cresceu ao mesmo tempo em que a renda média declinava em termos reais (Baltar et al., 2010). 
a têxtil), cresceram no período a taxas inferiores às do salário mínimo (Horta Barbosa, 2012).

Quando se considera a evolução do salário médio por tamanho do estabelecimento, a principal constatação é o declínio relativo do salário médio em relação ao salário mínimo nos estabelecimentos maiores, isto é, naqueles em que o salário médio é mais alto. Nas microempresas, os salários médios cresceram mais do que nas maiores em função da maior formalização do emprego e do peso na estrutura salarial do salário mínimo.

Quadro 6

Salário mínimo real e salário médio real habitual nas RM e em proporção ao salário mínimo $(\mathrm{em} \mathrm{R} \$)$

\begin{tabular}{|l|c|c|c|c|c|c|}
\hline & $\begin{array}{c}\text { SM } \\
\text { Real }\end{array}$ & $\begin{array}{c}\text { Empregados } \\
\text { do Setor } \\
\text { Público }\end{array}$ & $\begin{array}{c}\text { Empregados } \\
\text { do Setor } \\
\text { Privado }\end{array}$ & $\begin{array}{c}\text { Empregados } \\
\text { do Setor } \\
\text { Privado com } \\
\text { Carteira }\end{array}$ & $\begin{array}{c}\text { Empregados } \\
\text { do Setor } \\
\text { Privado sem } \\
\text { Carteira }\end{array}$ & $\begin{array}{c}\text { Trabalhadores } \\
\text { por conta } \\
\text { própria }\end{array}$ \\
\hline 2002 & \multirow{2}{*}{379,30} & $\begin{array}{c}2271,78 \\
(5,99)\end{array}$ & $\begin{array}{c}1424,21 \\
(3,75)\end{array}$ & $\begin{array}{c}1578,88 \\
(4,16)\end{array}$ & $\begin{array}{c}996,96 \\
(2,6)\end{array}$ & $\begin{array}{c}1399,43 \\
(3,69)\end{array}$ \\
\hline \multirow{2}{*}{2005} & \multirow{2}{*}{423,74} & $\begin{array}{c}2144,19 \\
(5,00)\end{array}$ & $\begin{array}{c}1304,99 \\
(3,08)\end{array}$ & $\begin{array}{c}1443,35 \\
(3,41)\end{array}$ & $\begin{array}{c}948,96 \\
(2,24)\end{array}$ & $\begin{array}{c}1148,86 \\
(2,71)\end{array}$ \\
\hline \multirow{2}{*}{2007} & \multirow{2}{*}{512,51} & $\begin{array}{c}2400,84 \\
(4,6)\end{array}$ & $\begin{array}{c}1389,35 \\
(2,71)\end{array}$ & $\begin{array}{c}1506,78 \\
(2,94)\end{array}$ & $\begin{array}{c}1027,10 \\
(2,00)\end{array}$ & $\begin{array}{c}1281,62 \\
(2,50)\end{array}$ \\
\hline 2009 & \multirow{2}{*}{566,43} & $\begin{array}{c}2631,48 \\
(4,64)\end{array}$ & $\begin{array}{c}1467,61 \\
(2,59)\end{array}$ & $\begin{array}{c}1573,41 \\
(2,77)\end{array}$ & $\begin{array}{c}1092,04 \\
(1,92)\end{array}$ & $\begin{array}{c}1378,73 \\
(2,43)\end{array}$ \\
\hline 2011 & 597,05 & $\begin{array}{c}2799,52 \\
(4,68)\end{array}$ & $\begin{array}{c}1555,99 \\
(2,60)\end{array}$ & $\begin{array}{c}1619,60 \\
(2,71)\end{array}$ & $\begin{array}{c}1274,74 \\
(2,1)\end{array}$ & $\begin{array}{c}1481,02 \\
(2,48)\end{array}$ \\
\hline
\end{tabular}

Fonte: IBGE/PME Ipea Regiões metropolitanas de Recife, Salvador, Belo Horizonte, Rio de Janeiro, São Paulo e Porto Alegre. Série deflacionada pela média ponderada do INPC das regiões.

Quadro 7

Salário médio mensal em mínimos por setor de ocupação

\begin{tabular}{|l|c|c|c|}
\hline & 2002 & 2006 & 2009 \\
\hline Salários & 4,3 & 3,7 & 3,3 \\
\hline Agricultura & 2,5 & 2,1 & 2,1 \\
\hline Pesca & 1,7 & 1,8 & \\
\hline Indústrias Extrativas & 6,4 & 5,2 & 8,5 \\
\hline Indústrias de Transformação & 4,7 & 3,8 & 3,5 \\
\hline Eletricidade, Gás e Água* & 9,7 & 9,1 & 7 \\
\hline Construção & 3,3 & 2,7 & 3 \\
\hline Comércio, reparação de veículos, objetos pessoais e domésticos & 2,6 & 2,2 & 2,1 \\
\hline Alojamento e Alimentação & 2 & 1,6 & 1,6 \\
\hline
\end{tabular}




Continuação
\begin{tabular}{|l|c|c|c|}
\hline & 2002 & 2006 & 2009 \\
\hline Transporte, Armazenagem e Comunicações & 4,9 & 4,7 & 3,3 \\
\hline Intermediação Financeira & 11,2 & 9,2 & 8 \\
\hline Atividades Imobiliárias & 3,6 & 2,8 & 2 \\
\hline Administração Pública & 5 & 4,5 & 4,5 \\
\hline Educação & 5,9 & 4,9 & 4,5 \\
\hline Saúde e Serviços Sociais & 3,7 & 3,2 & 3 \\
\hline Outros Serviços Coletivos & 3,5 & 2,9 & 2,4 \\
\hline
\end{tabular}

Fonte IBGE: Estatísticas do Cadastro Central de Empresas

\section{Estrutura produtiva, salários e preços relativos}

Em sua análise relativa ao período entre 1950/1970, Souza (1999) observou que o salário mínimo poderia ser considerado como a taxa de salários de base na indústria brasileira ${ }^{30}$. Tal constatação baseava-se na convergência entre o salário mínimo (cujo valor relativamente alto no início do período esteve em queda, sobretudo nos anos 1960) e o salário dos não qualificados nas indústrias mais débeis. Em contraste com esta evolução, os salários médios industriais se distanciaram crescentemente em relação ao salário mínimo. Tal constatação sublinhava (como anteriormente se discutiu) a relação inversa entre a taxa de salários e a abertura do leque salarial. Posteriormente, com a queda observada nos anos 1980 e parte dos anos 1990, o salário mínimo tornou-se menos significativo para os salários dos trabalhadores não qualificados no setor formal da economia, em particular na indústria de transformação. Nas décadas em que o valor do salário mínimo real caiu houve, para os salários pagos aos trabalhadores não qualificados nos setores mais organizados da economia, um deslizamento salarial e os salários descolaram do mínimo, na última década ocorreu justamente o contrário. Com a forte elevação deste salário na última década, a efetividade do salário mínimo sobre a taxa de salário tornou-se muito mais forte.

Com efeito, no setor formal da economia, a evolução do salário mínimo constituiu uma variável fundamental para a definição dos pisos salariais das principais categorias trabalhistas. Com base nos dados de 628 pisos salariais registrados no SAS-Dieese em 2008, observou-se que 56\% das negociações salariais estabeleceram pisos que não ultrapassaram 1,25 salários mínimos e $77 \%$ não superaram o valor de 1,5 salários mínimos. No comércio e no setor industrial, $80 \%$ das convenções e acordos coletivos fixaram pisos de até 1,5 SM. Esta convergência foi aumentando ao longo da década com os pisos mais baixos cada vez mais próximos do valor do salário mínimo. Com efeito, se em 2005 o valor médio dos

(30) “As evidências disponíveis no caso brasileiro mostram que o salário mínimo legal pode ser considerado como a taxa de salários de base na indústria brasileira durante as três últimas décadas" (Souza, 1999). 
pisos estabelecidos na indústria era de 1,47 SM; em 2011 este valor foi de 1,35 SM; o do comércio passou de 1,66 para 1,22 e o do setor de serviços de 1,91 para 1,48. Em particular, nas indústrias tradicionais e onde os sindicatos são mais débeis, a elevação do salário mínimo afirmou-se como uma negociação coletiva compulsória contribuindo para a elevação da base dos salários. Com o crescimento do valor do salário mínimo, a diferença existente em cada categoria entre os pisos médios e aqueles mais baixos foi também se reduzindo. Ou seja, na medida em que o salário mínimo institucional aumentava, ele tornava-se cada vez mais relevante para a organização da escala de remunerações.

Mas esta difusão e influência do salário mínimo não se limitaram ao mundo urbano. Aos poucos o salário mínimo foi se impondo na agricultura capitalizada. Embora o assalariamento formal seja relativamente pequeno na agricultura brasileira, a expansão dos mecanismos de fiscalização anteriormente comentada, ao lado de maior sindicalização, resultou tanto em um aumento da formalização (seguramente um processo menos visível no Nordeste) quanto na elevação dos salários pagos no trabalho assalariado informal (eventual).

Estas transformações na estrutura salarial não foram independentes das modificações ocorridas nos preços relativos. Estas contribuíram para que o substancial crescimento do poder de compra do salário mínimo fosse seguido entre empregadores e setores produtivos com diferentes níveis de produtividade (salárioproduto) sem uma pressão excessiva nos preços e inflação. Os novos preços relativos contribuíram para as mudanças observadas na estrutura salarial como o menor crescimento do salário médio e consequente redução do leque salarial. Com efeito, a valorização da taxa real de câmbio contribuiu ao longo da segunda metade da década para que os preços industriais aumentassem a uma taxa inferior a do salário mínimo. Ainda que o menor custo das matérias primas importadas (e das tarifas dos serviços de utilidade pública indexados ao IGP e situados num nível muito alto desde as privatizações dos 1990) tivessem contribuído para o menor crescimento dos custos industriais, o efeito combinado do câmbio valorizado, grande penetração das importações, elevação proporcionalmente maior dos preços agrícolas e aumento do salário mínimo levou a estratégias de contenção dos salários mais altos visando conter a elevação do custo do trabalho da indústria de transformação. Embora a incidência do salário mínimo na indústria seja bastante desigual entre setores, segundo a intensidade do uso do trabalho não qualificado, ela é, como se observou anteriormente, muito alta e significativa na formação dos pisos salariais. Com o mercado de trabalho aquecido, os sindicatos conseguiram em seus dissídios coletivos salários em geral superiores à inflação (Baltar et al., 2010), desse modo, foram as ocupações com maiores salários que relativamente diminuíram ou os salários mais altos que se ajustaram a um percentual inferior. 
Horta Barbosa (2012), com base nos dados da Funcex relativos aos coeficientes de penetração das importações por setores industriais, verificou que entre 2002 e 2009, tanto naqueles setores tradicionais (produtos têxteis, vestuário e calçado) quanto naqueles mais intensivos em capital (química, metalúrgica, equipamento de informática, máquinas e equipamentos), a concorrência externa e a valorização do câmbio afetaram a evolução do salário médio e mediano. Dois movimentos estiveram presentes: os setores mais afetados pela concorrência reduziram os postos de trabalho de maior qualificação e salários mais altos, ampliando a contratação para os de menor qualificação e salários; os salários dos trabalhadores mais qualificados cresceram menos do que os salários dos trabalhadores de menor qualificação fortemente colados com o mínimo.

Desta forma, na indústria de transformação, o menor ritmo de crescimento do salário médio em relação ao salário mínimo (e consequente piso salarial) decorreu tanto de uma redução no mix de qualificações ou de simplificação das posições intermediárias induzida pela competição de custos (fator mais importante) quanto de um estreitamento do leque salarial. Conforme se observou, os salários médios na indústria de transformação caíram significativamente em termos do mínimo e, do mesmo modo, reduziu o peso da indústria na massa salarial. O contrário se passou com a agricultura e com os bens e serviços não comercializáveis.

Com o preço dos bens e serviços não comercializáveis e com os preços dos serviços de utilidade pública, da indústria de extração e da agricultura valorizandose em termos dos bens industriais, o aumento do salário mínimo foi parcialmente compensado ou foi mais facilmente repassado aos preços (ainda que de forma parcial e desigual, devido ao regime de concorrência destas atividades) ${ }^{31}$. (Ver Gráfico 3).

Gráfico 3

Variação do salário mínimo nominal e de índices de preços setoriais (2000 = base 100)

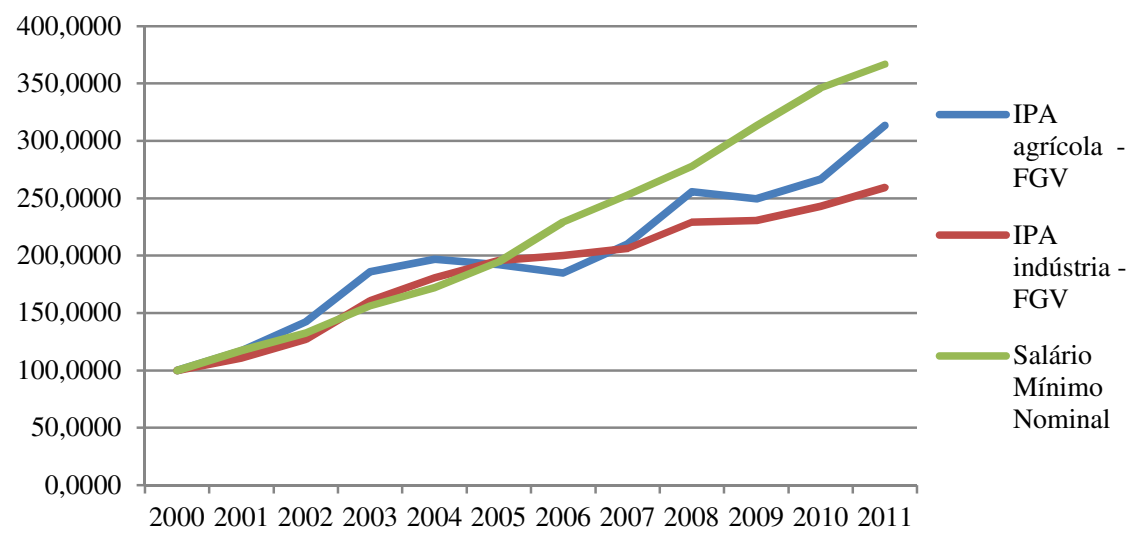

(31) A estimativa do seu impacto sobre os preços deve considerar sua influência na folha de pagamentos e o crescimento da produtividade. 
Assim, ainda que o salário médio tenha tido, em geral, um crescimento menor do que o mínimo, esta evolução foi superior à que se deu na indústria de transformação e muito diversa entre setores. Em primeiro lugar, nas indústrias extrativas, o salário médio descolou em relação ao crescimento do mínimo com os preços relativos do setor afirmando-se o setor relativo com maiores salários. Nos setores de salários mais baixos na agricultura, no comércio e na construção, a queda do salário médio em termos do mínimo foi muito menos acentuada. Deste modo, não apenas houve uma convergência intraqualificações nos principais setores empregadores de mão de obra como houve, também, uma maior convergência entre setores na medida em que os salários nestas atividades de salário mais baixo se aproximaram dos salários industriais.

Estas transformações põem em discussão a questão da liderança salarial. Em seu estudo sobre a dinâmica da formação salarial entre 1950 e 1970, Souza (1979) considerava que era a taxa de salários prevalecente na indústria que se propagava para as outras atividades, de forma que as mudanças nestes salários levavam a mudanças nos demais salários. A liderança salarial na grande indústria é uma hipótese cara na literatura institucionalista referida no início deste texto e decorre da maior autonomia salarial dos mercados internos das grandes empresas em relação às flutuações do mercado de trabalho. Souza (1979) atribui esta liderança salarial ao predomínio da indústria de transformação na determinação da taxa de crescimento da produção e do emprego do restante da economia.

Em contraste com este período, as transformações aqui examinadas identificam um deslocamento da liderança salarial. Devido às transformações no regime de crescimento induzido pelas exportações de commodities, à distribuição de renda do trabalho e dos novos padrões de consumo, na última década, o peso da indústria de extração, da agrobusiness e dos serviços para a expansão econômica foi substancialmente maior. Embora os contornos salariais industriais constituam grandes clusters de salários relativos, a maior exposição da indústria à concorrência externa e a valorização cambial introduziram limites ao aumento dos salários superiores ao que se deu nos demais setores; por outro lado, como o salário mínimo teve um aumento maior, a taxa de salários passou a gravitar mais e mais em torno deste valor. Foram os demais setores, em particular o da indústria de extração, o dos serviços de utilidade pública (eletricidade e gás) e de intermediação financeira que, no setor privado, estabeleceram os salários mais altos. Entretanto, estas atividades não formam contornos salariais a serem seguidos ou unidades amplas de determinação de salários. Desse modo, devido ao reduzido peso do emprego nestes setores para o emprego assalariado total, foram os salários pagos na administração pública (que ampliaram o seu peso relativo na massa de salários da economia brasileira e cujo salário médio se manteve estável relativamente ao mínimo) que se 
afirmaram como o principal contorno salarial, espalhando-se para diversas áreas, na educação, na saúde e serviços.

\section{"Efeito Farol" e "Efeito Propulsão"}

Tal como se depreende da distribuição das rendas do trabalho nas principais regiões metropolitanas, com a elevação do salário mínimo, o salário médio pago no emprego informal e a renda do trabalho autônomo aproximaram-se do salário pago no emprego formal. Os principais mecanismos que explicam a influência do salário mínimo sobre os salários informais e rendas do trabalho autônomo se confundem com aqueles examinados anteriormente sobre a mudança na estrutura do emprego, das instituições e dos preços relativos. A redução das atividades típicas de subsistência (que se confundem com as situações de pobreza) tornou mais homogêneas a base do mercado geral de trabalho e as fronteiras entre o trabalho não qualificado formal e informal (incluindo os "autônomos subordinados", isto é, aqueles que não possuem qualquer capital e desempenham, na realidade, um salário por peça ou recebem uma comissão por venda) se estreitaram à medida que seus integrantes possuem condições sociais não muito distintas. Há um contínuo fluxo na base deste mercado de trabalho que se caracteriza por muito ampla flexibilidade. Com a redução do desemprego e crescimento do emprego formal, a remuneração nestas atividades tende a convergir para o salário mínimo. Assim, com exceção das regiões rurais onde predominam as atividades de subsistência (particularmente presentes no Nordeste), nas demais e mesmo em atividades em que o emprego informal é muito alto e predomina o trabalho intermitente como na agricultura e na construção civil e nas atividades onde predomina o emprego feminino como no emprego doméstico, comércio e nos serviços, o salário mínimo afirmou-se como referência e base de negociação para a formação dos rendimentos tanto para empregadores quanto para empregados.

No trabalho autônomo não qualificado, isto é, no caso dos trabalhadores por conta própria sem recursos de qualificação, trabalhadores ambulantes, nas microempresas familiares, etc., em que predomina baixa renda, a expansão do salário mínimo e do emprego formal, bem como as transferências sociais como bolsafamília exerceu um "efeito propulsão" por meio dos dois mecanismos previamente mencionados. De um lado, devido ao seu positivo impacto sobre o emprego, o percentual da população ocupada nestas atividades foi reduzido, em particular daqueles estritamente compelidos por estratégias de sobrevivência ${ }^{32}$. Por outro, devido tanto à maior demanda sobre o setor de serviços quanto ao maior espaço para a elevação dos rendimentos, o número dos empreendedores aumentou (como atesta o Anuário da Sebrae). A conjugação destes dois mecanismos contribuiu para uma

(32) De acordo com o Anuário Sebrae 2011, o percentual dos trabalhadores por conta própria analfabetos e com ensino fundamental incompleto caiu ao longo da década. 
maior convergência das rendas do trabalho autônomo com as do trabalho assalariado. No campo, uma maior convergência de rendimentos se deu em decorrência das transferências sociais como o bolsa família e a aposentadoria rural (vinculada ao mínimo).

\section{Observações finais}

Discutiu-se neste texto que, com a recuperação do seu poder de compra (praticamente dobrando de valor em termos reais ao longo da década passada), o salário mínimo passou a exercer crescente influência sobre a formação da taxa de salários de amplos segmentos dos trabalhadores assalariados formais e informais e da renda dos trabalhadores autônomos sem recursos de qualificação. Tal circunstancia deve-se ao nível inicial muito baixo deste salário e a estrutura do mercado de trabalho brasileiro em que historicamente predominam os baixos salários. Investigou-se, em primeiro lugar, a elevada expansão absoluta e relativa do emprego assalariado formal sobre as outras formas de ocupação. Argumentou-se que a elevação do salário mínimo real, a redução da pobreza, as mudanças nos padrões de consumo, a demanda dos trabalhadores por emprego formal e fatores institucionais estiveram na base deste processo. Discutiu-se em seguida como o salário mínimo afirmou-se como referência para a remuneração de base da economia brasileira. Observou-se que este evoluiu a um ritmo superior ao do salário mediano e do salário médio, resultando em um adensamento da cauda inferior da distribuição. Mudanças na composição do emprego com o crescimento mais do que proporcional do assalariamento no setor de serviços, do comércio e da construção civil (que possuem salários mais baixos) e dos preços relativos contribuíram para esta relativa redução da dispersão salarial agregada. No caso da indústria de transformação, a convergência maior em torno do salário mínimo decorreu de dois aspectos: de um lado, com a evolução do mínimo, este (ou valores próximos a este) afirmou-se crescentemente como piso de amplas categorias, de outro, em função do menor crescimento relativo dos preços industriais e do grau de abertura da economia brasileira, a elevação dos salários de base resultou em maior contenção dos salários/postos de trabalho de salários mais altos contribuindo, também por este canal, para uma redução da dispersão salarial.

Por fim, discutiu-se o "efeito farol" e o "efeito propulsão" do salário mínimo sobre o setor informal e o trabalho autônomo. Para o primeiro, a expansão de maiores oportunidades de emprego bem como as transferências sociais ampliaram a sua influência direta como referência para os salários informalmente estabelecidos; para o trabalho autônomo, a influência do aumento do salário mínimo se deu indiretamente por meio da maior demanda (e consequente espaço econômico) sobre estas atividades, ao mesmo tempo em que contribuía (ao lado das políticas de transferência) para a redução da população ocupada nestas atividades. 
Embora parte destas transformações seja de natureza estrutural e institucional, elas evoluíram a partir de certas características do regime de crescimento que se afirmou naquela década. Com a desaceleração do crescimento ocorrida a partir de 2010 e consequente redução da taxa de crescimento do emprego formal (particularmente intenso na indústria de transformação) e maior desvalorização do câmbio, as pressões de custos aumentaram. Com a maior influência do salário mínimo sobre a taxa de salário e sobre o salário médio é possível que os aumentos decorrentes do reajuste anual possam vir a se traduzir em maiores pressões sobre os custos salariais e sobre os preços principalmente se movimentos voltados a recompor margens de lucro e/ou os contornos salariais (especialmente na indústria) estiverem ocorrendo. Neste sentido, a negociação de políticas de renda de forma a manter a política de valorização do salário mínimo e evitar um acirramento no conflito distributivo torna-se crescentemente importante ${ }^{33}$.

\section{Referências bibliográficas}

BACHA, E. Crescimento econômico, salários urbanos e Rurais: o caso do Brasil. Pesquisa e Planejamento Econômico, v. 9, n. 3, dez. 1979.

BALTAR, P.; SOUZA, P. R. Salário mínimo e taxa de salários no Brasil- Réplica. Pesquisa e Planejamento Econômico, v. 10, n. 3, 1980.

et al. Moving towards decent work. Labour in the Lula government: reflections on recent Brazilian experience. Global Labour University Working paper, 2010. (IRLE Working Papers).

BARBOSA DE MELO, L. F. et al. Rescuing the minimum wage as tool for a development in Brazil. International Journal of Labour Research, v. 4, n. 1, 2012.

BELSER, P.; SOBECK, K. At what level should countries set their minimum wages? International Journal of Labour Research, v. 4, n. 1, 2012.

CARDOSO, J. C. Determinantes da recuperação do emprego formal no Brasil: evidências para o período 2001/2005 e hipóteses para uma agenda de pesquisa. Revista de Economia Política, v. 29, n. 4 (116), 2009.

(33) Considerando as interações entre estrutura produtiva, estrutura de consumo e o padrão salarial, Souza (1979) observava que "Obviamente o Estado não dispõe de um sistema de informações tão aperfeiçoado que lhe permita estabelecer justamente o nível salarial que seja compatível com o conjunto de determinantes mencionados. O nível fixado em um dado momento será compatível ou não com os mesmos. Se o for terá vigência durante um período; se não, será alterado ou por variação nos preços, por efeito de crises econômicas que interrompem o processo de acumulação, ou ainda pela eclosão de movimentos reivindicatórios dos trabalhadores" (Souza, 1979, p. 160). 
CORSEUIL, C. H.; MOURA, R.; RAMOS, L. Determinantes da expansão do emprego formal: o que explica o aumento do tamanho médio dos estabelecimentos? Ipea, 2009. (Texto para Discussão, n. 1450).

DUNLOP, J. Wage contours. In: PIORE, Michael. Unemployment \& inflation institutionalist and structuralist views. M. E. Sharpe, Inc., 1979.

FONTES, A.; PERO, V.; BERG, J. Low-paid employment in Brazil. International Labour Review, v. 151, n. 3, 2012.

HORTA BARBOSA, L. M. A evolução recente da distribuição de renda brasileira sob a ótica das estruturas sócio-ocupacionais. Dissertação (Mestrado)-IE. UFRJ, nov. 2012.

IBGE. PNAD, vários números.

IBGE. PME, vários números.

IBGE. Estatísticas do Cadastro central de Empresas, vários números.

ILO. Update on minimum wage development. Committee on Employment and Social Policy, Governing Body, 304 ${ }^{\text {th }}$ session. Geneva: International Office, 2009.

ILO. Global Wage Report 2012/13. Geneva: International Office, 2013.

LEE, S.; SOBECK, K. A low wage work: a global perspective. International Labour Review, v. 151, n. 3, 2012.

LEMOS, S. A survey of the effects of the minimum wage in Latin America. Leicester: University of Leicester, Economics Department, University Road, 2007.

LEWIS, W. A. Economic development with unlimited supples of labour, The Manchester School, v. 22, n. 2, p. 139-191, 1954.

NERI, M.; GONZAGA, G.; CAMARGO, J. Salário mínimo, efeito farol e pobreza. Revista de Economia Política, v. 21 n. 2, 2001.

PIORE, M. Unemployment and inflation: an alternative view. In: PIORE, Michael. Unemployment \& inflation institutionalist and structuralist views. M. E. Sharpe, Inc., 1979.

SABÓIA, J. Elasticidades dos rendimentos do trabalho em relação ao salário mínimo: experiência de um período recente de crescimento do salário mínimo. Economia e Sociedade, Campinas, v. 19, n 2 (39), 2010.

SERRANO, F.; SUMMA, R. Macroeconomic policy, growth and income distribution in the Brazilian economy in the 2000s. Investigación Económica, v. LXXI, n. 282, 2012. 
Carlos Aguiar de Medeiros

SOUZA, P. R. (1979). Salário e emprego em economias atrasadas. Campinas: Unicamp. Instituto de Economia, 1999.

SEBRAE. Anuário, 2011.

STIRATTI, A. The theory of wages in classical economics. England: Edward Elgar Publishing Limited, 1991. 